\title{
Dramatising learning development: towards an understanding without definition
}

Jason Eyre

De Montfort University, Leicester UK

\section{Tracy Slawson}

De Montfort University, Leicester UK

\section{Abstract}

As learning developers increasingly seek recognition of their practices as a coherent and shared approach to teaching and learning in higher education, the notion of a 'definitive' understanding of learning development may appear an appealing prospect, one that promises clarity in recognising, understanding and valuing learning development. However, attempts at definition should be approached with caution, as they can be founded upon assumptions that permit no scope for evolution or change. Drawing on the philosophical work of Gilles Deleuze (1967) and his concept of the virtual, this paper problematises the idea of there being a 'clear and distinct' definition of learning development, arguing instead for a 'distinct and obscure' concept of learning development open to creative evolution.

Keywords: recognition scheme; professional development; philosophy; Gilles Deleuze.

\section{Introduction: a learning developer walks into a bar...}

A learning developer walks into a bar. She orders a drink and gets chatting with some strangers. 'So what do you do?' one of them asks. How does she answer this question? She could reply with: 'I'm a learning developer'. What is the likely response to this answer? Recognition? Misapprehension? Perplexity?

This paper presents a philosophical discussion of learning development as a set of distinct practices, and in particular focuses on the question 'What is learning development?'. The 
discussion draws on the thought of Gilles Deleuze and Félix Guattari (1994), in particular Deleuze's (1967) concept of the virtual, in order to critique the notion that there can, or should be, a 'clear definition' of learning development. We argue that there are ways and means of obtaining a shared understanding of learning development as a distinct set of practices without recourse to fixed notions of what these practices should be, and in so doing emphasise the openness and vitality of learning development. The aim throughout is to stimulate thought and seed discussion of issues around identity, practices, and values that we feel are important to consider as learning development evolves, and to encourage an engagement with philosophy as a way to approach these issues.

Let's get back to that bar. If our sociable learning developer was instead a doctor, a lawyer, or a teacher, we might expect a degree of recognition from these strangers on hearing what she does, for these latter jobs are well-established professions. Our strangers may even ask follow-up questions: 'A doctor? Are you a specialist, or are you in general practice?'; 'A lawyer? What area of the law?'; 'A teacher? Primary or secondary?'. In each case, we might expect there to be an understanding that these professions are not monolithic but consist of sub-branches and specialisms. In a similar vein, the strangers may respond with stereotypes or clichés, representing partial knowledge of what the profession entails ('A teacher? I'd love to have all those holidays!'). Even so, a cliché represents some kind of recognition, however misguided or lacking in understanding. At present, a learning developer might not expect this level of recognition from a group of strangers, let alone a high degree of understanding.

It is perhaps unlikely that our strangers would immediately recognise the label 'learning developer' as they might with 'doctor', 'lawyer' or 'teacher', and no follow-up questions regarding specialisms or stereotypical assumptions would likely be forthcoming. There are some clues in the label as to what such a job might entail (learning - 'are you some kind of teacher?'; learning and development - 'you work in Human Resources?'), and some of our strangers may pick up on one or more of these, depending on their own knowledge and background. Most likely, we would suggest (and any learning developer reading will have their own view on this) the response would be: 'A learning developer? What's that?'.

So rather than recognition or misapprehension, at the present time the label 'Learning Development' is likely to engender some degree of perplexity (empirical studies to test this contention would of course be welcomed). Given this, it is also likely that our learning 
developer would not use the label at all, but may attempt some kind of pre-emptive explanation:

'I'm a university lecturer'.

'I work in a university'.

'I'm in education'.

'I help students with their writing'.

'I work in a study skills unit'.

[Insert favourite self-description here].

It is likely that the learning developer, when faced with the question 'What do you do?', would consider their audience and the likely impact of their answer upon them. In our example, we had our learning developer meet some strangers in a bar, but learning developers also spend at least some of their time in other places, not least on a university campus - in a classroom, in meetings, in chance encounters in the car park. The audience here might perhaps be more familiar with the role (and certainly, 'I work in a university' is not going to illuminate a student or fellow academic). The way any response is then phrased depends on the effect the learning developer wishes to produce on their interlocutor, and status may be a consideration, consciously or unconsciously. In our bar room scenario, 'I work as a university lecturer' might perhaps be chosen ahead of 'I help with study skills' for this reason. In the absence of a recognisable label, our selfdescriptions aim not only to describe what we do, but also to convey something of the value of our practices. Hence, when we talk of value and values in relation to practice, we are referring to the extent to which our practices are worthy of pursuit, both in our own estimation and in the opinion of others.

To summarise, the way others apprehend the identity of learning developers matters in at least three ways: Firstly, in terms of recognition of the role in broad terms, as a profession/discipline/field of practice with some kind of distinctive identity; secondly, in terms of an understanding of what such a role might entail in practice, as opposed to misapprehensions or clichés; finally, in situations where there is some degree of recognition and understanding (such as in the university itself), there is an additional concern for the status of the role and how it is valued. In the absence of what we might call 'clarity' about these issues among non-learning developers, we may find what we do unrecognised, misunderstood, and our status misrepresented. It may be that the label 
'learning developer' may have some utility in addressing all three of these concerns, particularly as it becomes better understood. Steven Briggs (2018) sets out these issues in relation to the newly introduced (as of 2018) certified practitioner scheme, but at the present time, the title 'learning developer' itself is not sufficiently well known to carry with it the meanings we might wish to convey.

\section{The appeal of the definitive}

Issues around identity, and the question 'What is learning development?', are therefore not merely trivial concerns for the learning developer but impact on the recognition, understanding and status of what we do in our interactions with others. The clarity of our response to the question 'What do you do?' - or the lack of clarity - perhaps speaks to the uncertainty of how a nascent field of practice like learning development both sees itself and is seen by others (see Hilsdon, 2018). As a result of this, we perhaps find ourselves drawn towards attempts to obtain this kind of clarity - a definitive understanding of learning development that captures the essence of what it is, and what learning developers do; something that can be summarised and communicated efficiently and effectively, thereby mitigating the risks of being misunderstood.

For learning development, the following characterisations are offered as instructive and in some way representative of what has been written on the subject in recent years:

Learning Development is a complex set of multi-disciplinary and cross-disciplinary academic roles and functions involving teaching, tutoring, research, and the design and production of learning materials, as well as involvement in staff development, policy-making and other consultative activities. (Hilsdon, 2011, p.14)

...we argue for Learning Development to be allowed to be understood as a set of socio-political or emancipatory practices designed to empower students, from a range of diverse contexts, for 'action'. (Sinfield et al., 2011, p.55) 
LD promotes the development of students' academic 'voice' through enhancing their understanding of academic conventions, developing critical thinking and reflection strategies, written and verbal communication skills, writing and creativity. (Winter et al., 2015, p.2)

We can add to these summaries provided by the Association of Learning Development on Higher Education (2018) and the Journal of Learning Development in Higher Education (2018) on their respective websites, along with characterisations presented by the likes of Samuels (2013); Rust (2009); and Bishop et al. (2009), to present just a few illustrative examples, to which the reader could likely add a few of their own.

While there may not be any glaring inconsistencies across these various characterisations of learning development, they cannot be said to be identical, and none could lay claim to be definitive (nor do they attempt to make such a claim). Even so, while each author seeks to emphasise one aspect or another of learning development values and practices, these accounts make clear that there is a high degree of shared understanding about what learning development is all about, and each account has its own merit. Given this cohesiveness and shared understanding, there is perhaps a temptation to drill down further to the bedrock of what learning development is, its essential features, its essence.

We are not necessarily against such an exercise. Shared understanding, common cause, and a sense of professional identity and cohesion are all laudable aims, for they can be empowering to the practitioner in fostering a sense of community, of belonging, and of solidarity in a changeable higher education environment. Furthermore, it will be clear to many colleagues that if we don't somehow define ourselves, other actors in the higher education sector may seek to define us for themselves in ways that may be antithetical to our own shared professional values. In this sense the 'status' of learning development relates not simply to how good we might want to feel about ourselves, but to our capacity to act and exert influence, to engage in the practices that we value. Notwithstanding these reasons, in this paper we argue that attempts to appeal to a 'definitive' understanding of learning development needs to be understood as being not without a degree of risk. Indeed, we argue that an understanding constructed as 'definitive', while seemingly banal and uncontroversial is, in fact, inherently problematic. 


\section{'Clear and distinct'}

Why is this so? Well, the very question 'What is...?' is bundled up with certain ontological assumptions. That is to say, the question 'What is...?' itself is based on potentially contestable assumptions about the nature of our being. This might sound somewhat esoteric, so let us look at why this matters.

Our learning developer is now back at work. The team she works in is recruiting to a new position, and her manager has asked for a copy of her role profile to base the new position on. She locates the document and, while looking over it, our learning developer notices how different the various focuses of the role profile (written three or four years ago) now seem in relation to the work she is currently engaged in. She comments on this to her manager who points out that 'things have moved on from the way they were back then' and 'you've really made the role your own, playing to your strengths and the changing needs of the team'.

Another scenario: our learning developer is contacted by the university's research support office, who oversee support for research staff. They cite her work in supporting the writing of research students and wonder if, given her expertise and experience, she would be able to offer a workshop for staff researchers as well? She is happy to oblige, delighted even, but then realises that the stated remit of her team is to support students, not staff. She wonders if turning her attentions to the support of staff might in some way be seen as a problem.

A final scenario: in a one-to-one tutorial with a student, our learning developer is asked a question about research methods. This level of 'content knowledge' is typically left to the teachers on a programme of study to address, but the learning developer sees that the student's progress could be advanced significantly with just a simple explanation of a routine concept that she herself, as a researcher, understands well. Should she address the substance of the question or defer to the expertise of the academics in the course of study?

All three of these scenarios are plausible examples of what happens when you fix (that is, write down) the 'role' and/or 'remit' of a learning developer or learning development team, or, in the case of the final scenario, where there is a tacit understanding of what is 
expected. Here we have a tangible expression of the 'What is...?' question, framed in terms of 'What is it you will do?'. Of course, this kind of articulation of role and remit happens all the time, and we wouldn't expect to be able to proceed in the modern university with vague suggestions or half-baked indications about what learning developers are going to do. Rather, we are obliged to be accountable and transparent in our practices, often with targets and deliverables to adhere to, and this requires that our activities be articulated, documented, and communicated. However, the examples are intended to highlight the fact that, in spite of this 'fixing down' of individual roles or team remits, there remains a residual need to flex, to evolve our practices, to be (in managerial terms) 'agile and responsive'. If we rigidly stuck to our respective role profiles for years on end, or refused to countenance undertaking activities that seemed to be in tension with our 'core mission' or commonly understood parameters, we might be seen as inflexible, bureaucratic, or lacking in vision. The comforts of a fixed understanding of our work, of having a 'clear' framework to which we can (and must) adhere can, over time, become a restrictive cage.

Malcolm and Zukas (2009) highlight the tensions inherent in academic practices between the need for clarity and the need to be 'messy', and point to the imperative towards categorisation that prevails in contemporary higher education. Those activities which cannot be clearly demarcated and understood, institutionally speaking, are liable to be 'othered', and devalued. Here we see another expression of the need for 'recognition' in learning development, that is, to mitigate against such an 'othering' by the institutions we work within. Hence, we can perceive a tension in learning development between the need to conform to some form of communicable categorisation on the one hand; and on the other, the need to defy such categorisations in order to enable responsiveness to the environment in which learning development operates; that is, to permit evolution.

Philosophers such as Nietzsche are critics of this perceived need for clarity in our attempts to understand our world. Nietzsche dismisses such attempts as 'Platonism', the view that there exists in the world a set of pre-determined and perfect Forms, if only we could uncover them (Deleuze, 1990, p.253). When we fail to do so, finding only imperfection, we are liable to blame ourselves or others for this failure. Instead, Nietzsche (and those that followed and developed his work, including Deleuze) insists that there are no Forms, no fixed ideal of the way things are, only becomings. The world is not an expression of eternal, unchanging entities emanating from a transcendent domain of Forms, but a 
dynamic, ever-changing, messy, domain of things in constant flux, subject to forces and relations of power.

In this way, the very idea that we might be able to answer the question 'What is learning development?' carries with it the assumption that such a question is even answerable, perhaps by somehow discovering the 'true form' of learning development. But, as anyone who has talked to learning development colleagues at other institutions knows, the way learning development is expressed in different places and at different times is... different. Any attempt at a 'definitive' understanding of 'What is learning development?' is soon overcome by the prevailing tendency towards particular practices rather than universal ones, or else our attempts to reach a common understanding fall short of something resembling anything definitive, and looks instead more like an exhausted, irritable consensus.

\section{'Distinct and obscure'}

This does not mean that we are destined to dwell in a permanently confused state in which all is noise and no sense at all is possible. Rather, we must refocus our attention onto what we can hope to achieve in a positive sense. In his 1967 lecture The method of dramatisation, the French philosopher Gilles Deleuze (1925-1995) draws a distinction between what he sees as the Cartesian ideal of the 'clear and distinct' with an idea he draws from Leibniz - the 'distinct and obscure'.

To paraphrase, for Deleuze there is an objective, material world that is 'out there'. This world is dynamic, always changing. What we refer to as 'reality' is not simply that which has a material form, but also the conditions whereby material things are able to change. Deleuze does not distinguish between the 'real' and the 'possible' (which is not real, but which somehow might become real), but between the 'actual' and the 'virtual', both of which can be said to be real. In this way of thinking, every actual thing (that we can see, touch, sense in some way) also possesses a degree of virtuality. Manual DeLanda (2011) provides a good example of this: imagine a knife. It has a material reality - it is made of metal, has a wooden handle, is sharp, and so on. These are material properties of the actual knife, and we can measure them. But the knife also has virtual properties. One of these is its capacity to cut. We can take the knife and use it to cut something - at which 
point this capacity is said to be 'actualised' (that is, we have actually cut something). But we can also imagine a situation where we never use the knife to cut something. Perhaps it stays in its packaging, at the back of a cupboard for all eternity: that knife's capacity to cut remains a real property of the knife, just one which has never been actualised.

We can think of that knife's actual properties as 'distinct' - we can weigh it, measure it, take a photograph of it, represent it in various ways. It is distinguishable as a knife and not something else. Insofar as that is our interest, we can also say that these actual, measurable properties are 'clear'. But what is not 'clear' is what the knife might be used for in the future. Will it be used to cut something? Maybe, maybe not. The virtual properties of the knife lack clarity, for we don't know how it will be used, or even if it will be used at all. These are virtual properties of the knife and these virtual properties can never be fully clear to us until they are actualised. While the actual properties of a thing are distinct (measurable, identifiably belonging to that thing), the virtual properties of a thing must remain obscure until they are actualised. We don't know what is going to happen until it does - and suddenly all becomes clear. Likewise, we might take the knife and instead of using it to cut something, find some way of dulling the blade so that it no longer has the capacity to cut. This blunt knife remains largely unchanged: it still looks the same, weighs the same as before. Perhaps it might be used as an ornament rather than as a cutting tool. Nevertheless, the physical changes to the actual knife have altered its virtual properties it no longer has the capacity to cut. In this way, changes in the domain of the actual have an effect on the virtual, just as the virtual 'structures' what can be actualised.

Our learning developer lives and works in this dynamic world of the actual and the virtual. There are things that she actually does - you can measure them if you like: the number of students seen, the number of lectures delivered, page views for the online resources she has developed. You can document all of these actual activities, clearly and distinctly. But she also possesses virtual capacities as well, latent properties that may or may not be actualised - but which are nevertheless real. When she received the e-mail, our learning developer had the capacity to support the writing skills of staff, but this virtuality was only actualised when she was asked to do this by the research support department. Over the years she has developed the capacity to be able to walk a student through some of the basics ideas of research methods, but this was not foreseen as relevant to her learning development practice until a student asked her to do it. After three or four years of responding to the environment, of being flexible, 'agile', in this way, the work she does has 
'moved on' from her original role profile, and of course her original role profile could not have anticipated that these things would occur in the future. How could it? There may well be an expectation that everything we do should be 'clear and distinct', but the reality of the dynamic world we live in means that such an expectation is unrealistic.

When we seek to define learning development, then, when we answer the question 'What is...?', we run the risk of circumscribing the virtualities inherent in such work, of shutting down what we, as practitioners, are capable of doing. Definition becomes a boundary. We can see this boundary in evidence in other, more established professions - the doctor, the lawyer, the teacher. The limits and expectations in these domains are enacted through formalised codes of practice, processes of registration, and compliance regimes. A boundary circumscribes virtualities in these professions in order to ensure that certain proscribed or unvalued practices are not actualised. The boundary here represents a clear demarcation of what is permissible and is enforced through certain relations of power. But these are mature professions in the sense that the power relations at play within and around them have been stabilised ('territorialised' to use Deleuze and Guattari's (1994) language). Readers may recognise attempts to stake out a stable territory in this way in other, related areas within higher education (e.g. in Educational Development, as detailed by Samuels, 2013). The imperative to codify accepted practices in this way can be seen as the price that must be paid (but to whom, and at what cost?) in order to occupy a certain niche within the higher education milieu. Arguably, learning development remains an open prospect, whose very openness is an indication that relations of power around it remain unresolved and contestable.

Instead of trying to be 'clear and distinct', we could perhaps instead aspire to be 'distinct and obscure'. Distinct because, yes, there are a set of practices we can identify as learning development; and yes, there are common values that we share. It is certainly the case that learning development practices become clear as they are actualised - in our activities, our conversations, in the way we think about our work. But this is not the end of it. There remains a 'virtuality' to what we do - capacities that have yet to be actualised, or even anticipated. These are just as much a part of the reality of learning development and represent the space through which our practices might evolve, just as a fire burns in the space between the logs.

This account has perhaps been rather abstract, but our hope is that our colleagues can 
see where we are coming from. We can hear the pause as many of you think: 'Okay, sure, let's not pin ourselves down and all that, but... what do I tell my managers? They're not going to buy all this obscurity stuff'. To answer this anticipated question, our point here is not that we don't account for ourselves as learning developers. Indeed, we must. We started this discussion by talking of recognition, understanding, and status, arguing that learning developers have need of all three in order to work effectively in our various roles. To achieve any of these things, we need to account for ourselves - our perspectives, our practices, our value (and our values). In practical terms, a learning developer can come to an understanding of our own practices (and the practices of our teams) through a process of tracing of the dynamics that constitute what we do - the various actors, agents, forces, interests, power relations, that comprise our working lives. This is an exercise in understanding our practice in the particular case. There is value in this, for in doing so, we can then speak with one another (and our managers) and compare notes - not to uncover some universal 'truth' about our practices, but simply to lay them side by side in order to notice patterns, to share experiences and to 'speak alongside' one another. The key to all of this, following Deleuze's thinking, is to initially confine the scope of such an exercise to what is actually the case, rather than seeking to devise or uncover an assumed 'universal' understanding, a common denominator, or a generalised view of what constitutes the 'true' learning development. From that point, once a perspective is obtained, we can venture outside, so to speak, and see what others have discovered - not to 'get to the bottom of it' (there is no bottom), but to note the tendencies across a range of practices. As we have argued, seeking a kind of fixed 'ideal' of practice is both illusory and unhelpful, as it sets one understanding against another in a futile process of contradiction without end ('this, not that'), whereas the interest should lie in the dynamics of relations, in the tendencies across practices, in the drama:

The clear and the distinct is the claim of the concept in the Apollonian world of representation; but beneath representation there is always the ldea and its distinctobscure ground, a 'drama' beneath all logos. (Deleuze, 1967, p.101)

The early work on professional certification for learning developers shows promise in this regard, as it sets out no 'clear and distinct', codified, criteria for the practitioner to 'tick off', no defined role or 'core practices', but rather a broad but coherent set of values for the practitioner to consider and respond to, which in turn is then assessed by members of the ALDinHE community (Briggs, 2018). This at least provides the basis for a distinctive 
understanding of learning development but retains the space for a necessary degree of obscurity and dynamism.

\section{A 'pedagogy' of learning development}

In their book What is Philosophy (1994), Deleuze and his collaborator Felix Guattari suggest that a concept moves through three ages as it develops (Deleuze and Guattari, 1994, p.12), and we can include here the 'concept' of learning development. A concept starts in what the authors refer to as an age of the 'encyclopedia', in which the creation of a concept is a function of our individual perspective. We can see an example of this whenever we examine our own individual practices of learning development, for our dayto-day work is understood and known by ourselves, as reflective individuals, our myriad experiences accumulating much as the entries in an encyclopedia accumulate. The following age Deleuze and Guattari refer to as 'pedagogy', and it is in this age that a concept (and indeed, a field of practice unified under that concept) truly lives: the concept as a creative force. We can see this unleashing of potential occur as learning developers engage and share practices with one another, our perspectival individual experiences becoming part of a broader whole. Our various perspectives are enhanced and enriched as we learn from each other, creating (and actualising) a distinctive 'learning development'. Finally, however, as it becomes more established, a concept can become prone to stasis, in what Deleuze and Guattari refer to as the age of 'commercial professional training'. Here the concept is reduced to formulaic repetition, drained of life and energy, and conceived entirely in the actual without any sense of its inherent virtuality: entirely 'objective', but as a consequence merely a lifeless object. For learning developers, this would represent a stifling of our creative potential as we attempt to adhere to self-imposed criteria for compliance (or else imposed by others), with none of the creative 'obscurity' which permits our evolution as practitioners.

Deleuze and Guattari, in their writing on philosophy, caution against shifting from the dynamics of 'pedagogy' into the disastrous formalisms of 'commercial professional training': 
If the three ages of the concept are the encyclopedia, pedagogy, and commercial professional training, only the second can safeguard us against falling from the heights of the first into the disaster of the third - an absolute disaster for thought whatever its benefits might be, of course, from the viewpoint of universal capitalism. (Deleuze and Guattari, 1994, p.12)

\section{Conclusion}

There is in this a note of caution for us then, in our project of obtaining recognition, understanding and status for learning development. The 'absolute disaster of thought' represented by the third age of the concept is the point at which the concept of learning development, indeed the very notion of education which it seeks to underpin, ceases to be an active, living, entity, and becomes instead the 'clear and distinct' object of commodification and exchange, drained of its virtual capacities to evolve, '...overwhelmed by regimes of quality-control, coupled with an ultimately nihilistic, because empty, notion of excellence' (Standish, 2008, p.222). We have argued that it is better to determine what is distinctive about our work without recourse to any sense of there being a transcendent 'universal' understanding of learning development. Such an approach focuses our attention instead on the relational dynamics and tendencies inherent in each particular case of practice, and how they came to be that way. By recognising that there is no fixed ideal form of learning development, we preserve our virtual capacities to respond to our ceaselessly shifting world of higher education, and so too evolve along with our practices. Anything else would surely sell us out and sell us short. A learning developer walks into a bar. 'Damn', she thinks, 'We should have set it higher'.

\section{References}

Association for Learning Development in Higher Education (2018) About ALDinHE. Available at: http://www.aldinhe.ac.uk/about.html (Accessed: 25 May 2018).

Bishop, C., Bowmaker, C. and Finnigan, T. (2009) 'Mrs Mop, Mechanic and/or Miracle Worker: metaphors of study support', Journal of Learning Development in Higher Education, Issue 1, February, pp. 1-14. 
Briggs, S. (2018) 'Development of the ALDinHE recognition scheme: certifying the 'learning developer' title', Journal of Learning Development in Higher Education, Issue 13, April, pp. 1-11.

DeLanda, M. (2011) Metaphysics as ontology: Aristotle and Deleuze's realism [Online Lecture]. European Graduate School Video Lectures. Available at: https://www.youtube.com/watch?v=1ZjMKGTYfK4 (Accessed: 26 May 2018).

Deleuze, G. (1967) 'Appendix 1: The method of dramatization: paper presented to the Société française de Philosophie', 28 January, Bulletin de la Société française de Philosophie. LXII pp. 89-118.

Deleuze, G. (1990) The logic of sense. New York: Columbia University Press.

Deleuze, G. and Guattari, F. (1994) What is philosophy? London: Verso.

Hilsdon, J. (2011) 'What is learning development?', in Hartley, P., Hilsdon, J. and Keenan, C. (eds.) Learning development in higher education. Basingstoke: Palgrave Macmillan, pp.13-27.

Hilsdon, J. (2018) The significance of the field of practice 'Learning Development' in UK higher education. Thesis. Available at:

https://pearl.plymouth.ac.uk/bitstream/handle/10026.1/10604/2018Hilsdon10029559 EdD.pdf?sequence=1\&isAllowed=y (Accessed: 25 May 2018).

Journal of Learning Development in Higher Education (2018) Home page. Available at: https://journal.aldinhe.ac.uk/index.php/jldhe (Accessed: 25 May 2018).

Malcolm, J. and Zukas, M. (2009) 'Making a mess of academic work: experience, purpose and identity', Teaching in Higher Education, 14(5), pp. 495-506.

Rust, C. (2009) 'A call to unite in a common cause', Journal of Learning Development in Higher Education, Issue 1, February, pp. 1-5. 
Samuels, P. (2013) 'Promoting learning development as an academic discipline', Journal of Learning Development in Higher Education, Issue 5, March, pp. 1-22.

Sinfield, S., Holley, D., Burns, T., Hoskins, K., O’Neill, P. and Harrington, K. (2011) 'Raising the student voice: learning development as socio-political practice', in Hartley, P., Hilsdon, J. and Keenan, C. (eds.) Learning development in higher education. Basingstoke: Palgrave Macmillan, pp. 53-63.

Standish, P. (2008) 'The education concept', in Smeyers, P. and Depaepe, M. (eds.) Educational research: the educationalization of social problems. Belgium: Springer, pp. 217-226.

Winter, J., Barton, G., Allison, J. and Cotton, D. (2015) 'Learning development and education for sustainability: what are the links?', Journal of Learning Development in Higher Education, Issue 8, March, pp. 1-23.

\section{Author details}

Jason Eyre and Tracy Slawson are Senior Lecturers in Learning Development in the Centre for Learning and Study Support at De Montfort University, Leicester. 